\title{
Proximal Muscle
}

National Cancer Institute

\section{Source}

National Cancer Institute. Proximal Muscle. NCI Thesaurus. Code C91404.

A muscle located close to the trunk of the body. 